HETEROCYCLES, Vol. , No. , , pp. -. (C) The Japan Institute of Heterocyclic Chemistry

\title{
MEMORY OF CHIRALITY IN THE ELECTROCHEMICAL OXIDATION OF THIAZOLIDINE-4-CARBOXYLIC ACID DERIVATIVES ${ }^{\dagger}$
}

\section{George Ng’aNg’a Wanyoike, Yoshihiro Matsumura, Masami Kuriyama, and Osamu Onomura*}

Graduate School of Biomedical Sciences, Nagasaki University, 1-14, Bunkyo-machi, Nagasaki 852-8521, Japan. E-mail: onomura@nagasaki-u.ac.jp

${ }^{\dagger}$ Dedicated to Professor Emeritus Akira Suzuki, Hokkaido University, on his $80^{\text {th }}$ birthday.

\begin{abstract}
Memory of chirality in the electrochemical oxidation of thiazolidine-4-carboxylic acid derivatives was observed. The relatively larger size of sulphur atom than the oxygen atom for oxazolidine-4-carboxylic acid derivative may slightly improved the enantioselectivities of the oxidized products. The bulkier penicillamine derivative 1c furnished 2c with much better enantioselectivity $(91 \%$ ee) than that of the cysteine derivative $\mathbf{2 b}(85 \%$ ee). The presence of two extra dimethyl groups, for the penicillamine derivative improved the enantioselectivities of the thiazolidine derivatives from $85 \%$ ee to $91 \%$ ee.
\end{abstract}

The synthesis of optically active compounds on the basis of 'memory of chirality' continues to attract much attention in asymmetric synthesis. ${ }^{1}$ In our previous studies on asymmetric synthesis via memory of chirality, we reported that the non-Kolbe electrolysis ${ }^{2}$ of the oxazolidines afforded optically active N,O-acetals with up to $80 \%$ ee (Scheme 1 ). ${ }^{3}$ This highly enhanced enantiomeric excess was attributed to the bulkiness of the ring system as well as the $N$-protecting group. We report herein that the non-Kolbe reaction of thiazolidine-4-carboxylic acid derivatives proceeds more efficiently than that of the corresponding oxazolidines.
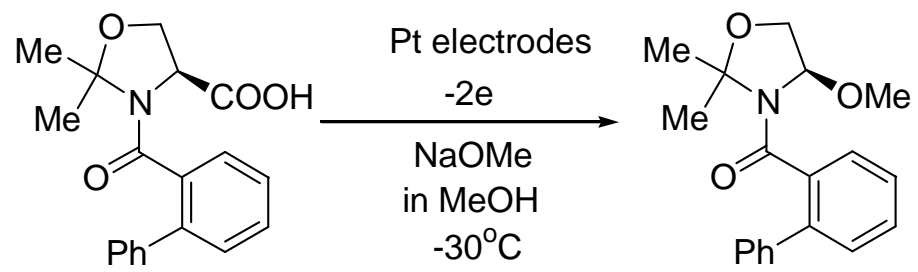

$80 \%$ ee

Scheme 1. Electrochemical oxidation of oxazolidine derivative 
Several thiazolidine compounds were synthesized and electrochemically oxidized in methanol. The $N$-benzoylthiazolidine compound 1a, derived from cysteine afforded a racemic $N, O$-acetal 2a when electrochemically oxidized using platinum electrodes in methanol at $-20{ }^{\circ} \mathrm{C}$. The use of graphite anode in the electrochemical oxidation of 1a afforded $2 \mathbf{a}$ with $22 \%$ ee in $72 \%$ yield (Scheme 2). These stereochemical results, albeit low, correlated well to those of the oxazolidine derivatives, $0 \%$ and $39 \%$ ee, for the platinum and graphite anode, respectively. ${ }^{4}$<smiles>CC1(C)SC[C@@H](C(=O)O)N1C(=O)c1ccccc1</smiles>

$1 \mathbf{a}$

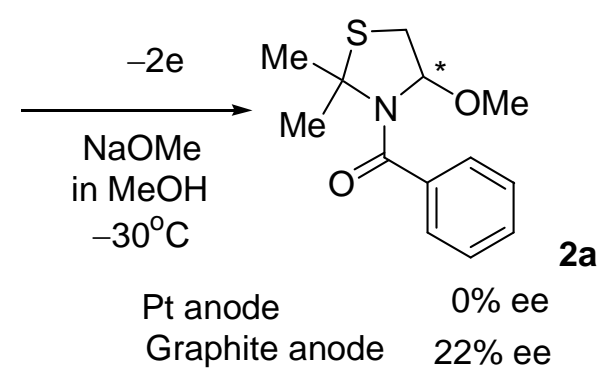

Scheme 2. Electrochemical oxidation of thiazolidine derivative 1a

Electrochemical oxidation of a more bulky $\mathrm{N}$-o-phenylbenzoylcysteine derivative $\mathbf{1 b}$ under the previously optimized reaction conditions using platinum and graphite anode, ${ }^{3,5}$ furnished $\alpha$-methoxylated product $\mathbf{2 b}$ with $85 \%$ ee and $80 \%$ ee for the platinum and graphite anode, respectively (Scheme 3 ). ${ }^{6}$<smiles>CC1(C)SC[C@@H](C(=O)O)N1C(=O)c1ccccc1-c1ccccc1</smiles>

1b<smiles>CO[C@H]1CSC(C)(C)N1C(=O)c1ccccc1-c1ccccc1</smiles>

$2 \mathbf{b}$

$85 \%$ ee $(58 \%$ yield ) $80 \%$ ee (56\% yield)

Scheme 3. Electrochemical oxidation of thiazolidine derivative $\mathbf{1 b}$.

This result shows that there was a slightly better enantioselectivity in the case of using platinum anode, $85 \%$ ee in the thiazolidine derivatives than that in the oxazolidine derivatives, $80 \%$ ee.

Treatment of $\mathbf{2} \mathbf{b}$ with acidic methanol at room temperature furnished almost racemic product, $1 \%$ ee after stirring for $17 \mathrm{~h}$ (Scheme 4).

$$
\text { 2b } 85 \% \text { ee } \quad \stackrel{\begin{array}{l}
\text { cat. } \mathrm{H}_{2} \mathrm{SO}_{4} \\
\text { in } \mathrm{MeOH}
\end{array}}{\stackrel{\text { rt, } 17 \mathrm{~h}}{\longrightarrow} \quad \text { 2b } 1 \% \text { ee }}
$$

Scheme 4. Racemization of $\mathbf{2} \mathbf{b}$ under acidic condition 
To improve the enantioselectivity, it was envisaged that the use of more bulky ring system could restrict the rotation of the amide $\mathrm{CO}-\mathrm{N}$ bond and thus promote the memory of chirality. On this basis, $\mathrm{N}$-acyl thiazolidine derived from optically active penicillamine was synthesized. Electrochemical oxidation of the penicillamine derivative $1 \mathrm{c}$ in methanol at $-30{ }^{\circ} \mathrm{C}$, using 10 equiv of $\mathrm{NaOMe}$ with platinum electrodes furnished $N$-acyl- $N, O$-acetal $2 \mathbf{c}^{7}$ with $91 \%$ ee in $54 \%$ yield (Scheme 5).

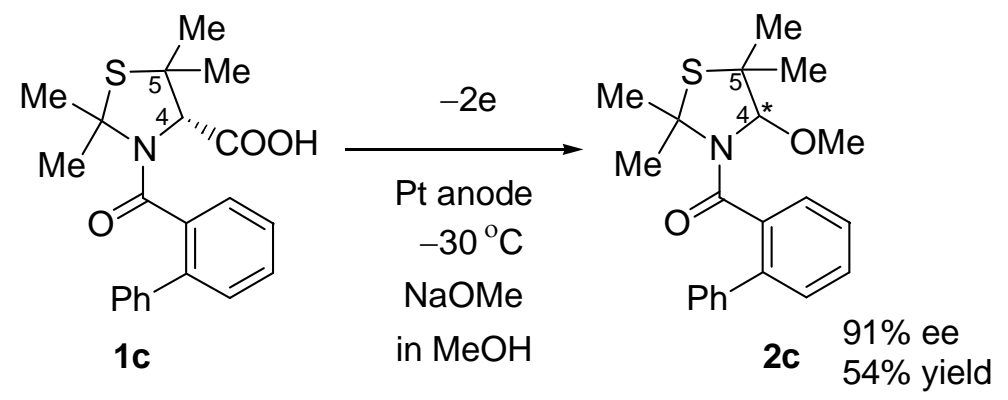

Scheme 5. Electrochemical oxidation of penicillamine derivative 1c.

This was a great enhancement in the enantiomeric excess, from $85 \%$ ee in the cysteine derivative $2 \mathbf{b}$ to 91\% ee in 2c. This improvement was ascribed to the presence of dimethyl groups at C5 in 1c. The racemization of $2 \mathrm{c}$ in acidic methanol afforded $2 \mathrm{c}$ in $3 \%$ ee (Scheme 6).

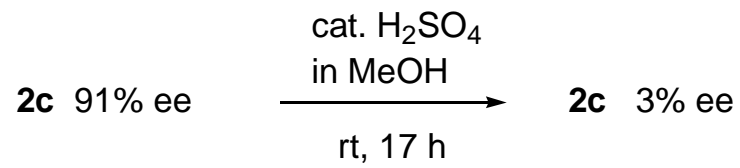

Scheme 6. Racemization of $2 \mathrm{c}$ under acidic condition.

The bulkier compound may have had a greater restriction of rotation of the o-phenyl group prompting an increased attack by the nucleophile, $(\mathrm{MeOH})$, from the less hindered side hence the larger enantiomeric excess.

In order to compare the electrochemical result with the chemical method, 1c was oxidized using $\mathrm{Pb}(\mathrm{OAc})_{4}$ in methanol at $-30{ }^{\circ} \mathrm{C}$. The chemical reaction proceeded slowly to afford $15 \%$ of $\alpha$-methoxylated product 2c in $86 \%$ ee after 6 days (Scheme 7). The major isomer in the chemical oxidation process had a similar configuration to that of electrochemical product as shown by the chiral HPLC analyses.

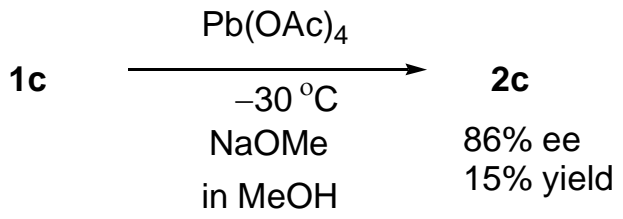

Scheme 7. Chemical oxidation of 1c. 
Direct assignment of the absolute configuration for compounds $\mathbf{2} \mathbf{b}, \mathbf{c}$ was not applicable, but the absolute configuration could be inferred on the basis of the following reactions. In order to deduce the absolute configuration of the methoxylated products and hence the plausible reaction mechanism for the thiazolidine derivatives, 2,3,5R-trimethyl-3-o-phenylbenzonylthiazolidine-4R-carboxylic acid (1d) ${ }^{8}$ was prepared from L-threonine $(\mathbf{A})^{9}$ (Scheme 8$)$.

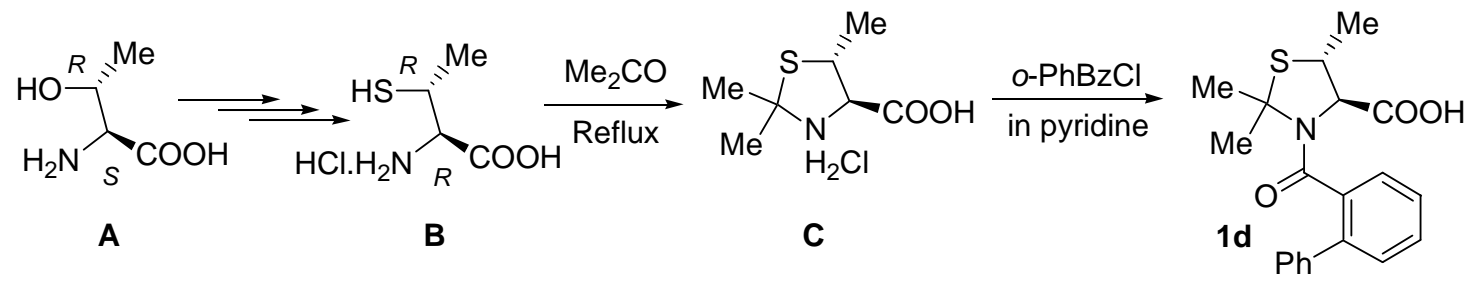

Scheme 8. Preparation of cysteine derivative 1d.

Electrochemical oxidation of $4 R, 5 R$-1d in methanol afforded $\alpha$-methoxylated compound $\mathbf{2} \mathbf{d}^{8}$ as a single diastereomer ( $>99 \%$ de) (Scheme 9).<smiles>CC1SC(C)(C)N(C(=O)c2ccccc2-c2ccccc2)C1C(=O)O</smiles>

1d

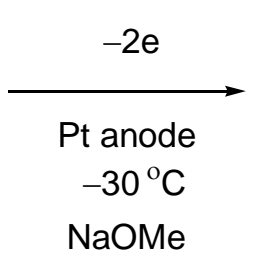

in $\mathrm{MeOH}$<smiles>COC1=C(C)SC(C)(C)N1C(=O)c1ccccc1-c1ccccc1</smiles>

2d $>99 \%$ de

Scheme 9. Electrochemical oxidation of 1d.

NOESY for $\mathbf{2} \mathbf{d}^{8}$ suggested that the methoxyl group and the 5-methyl had a trans-configuration and hence $\alpha$-methoxylation process proceeded mainly by introduction of the nucleophile, $(\mathrm{MeOH})$, from the same side (syn) as the carboxylate group to afford a retention product $4 R, 5 R-2 \mathbf{d}$ predominantly.

Interestingly, NOESY cross peaks were observed also between the aromatic protons and the 5-methyl protons of 1d and 2d. This correlation peaks clearly illustrated the actual position of the phenyl rings, which was deduced to be on the same side as the 5-methyl and on the opposite side of the carboxylic group.

Thus, the mechanism for the oxidative decarboxylation of the thiazolidine compounds is plausibly similar to that of the oxazolidine derivatives, albeit the enantioselectivities for methoxylated products for the thiazolidines were better (Scheme 10). 


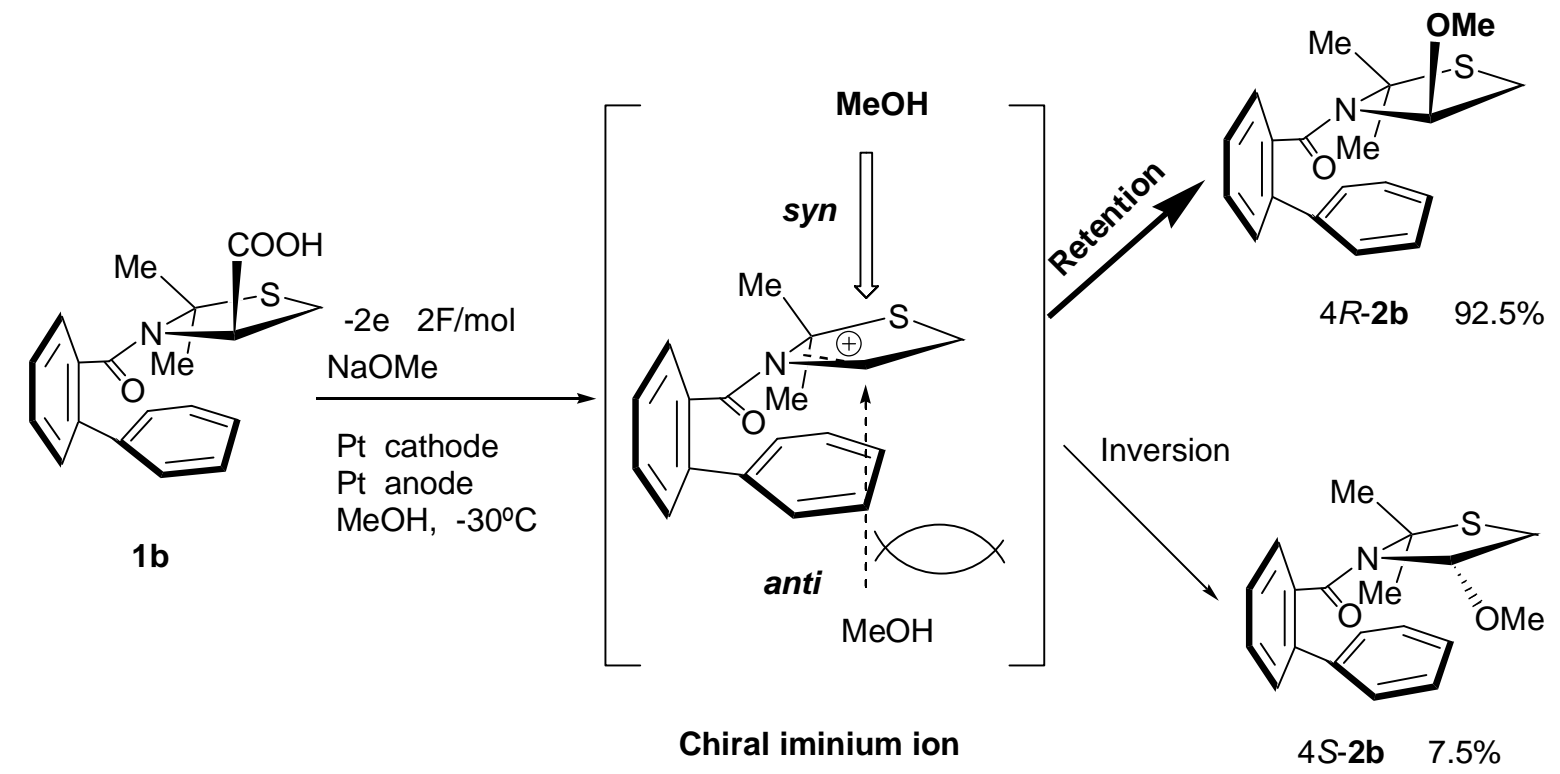

Scheme 10. Reaction mechanism for electrochemical oxidation of $\mathbf{1 b}$.

In summary, the thiazolidine compound $\mathbf{1 b}$ afforded $N, O$-acetal $\mathbf{2} \mathbf{b}$ with better enantioselectivity than that of previously reported oxazolidine. ${ }^{3}$ The relatively larger size of sulphur atom than the oxygen atom may be responsible for the difference in the enantioselectivities. The bulkier penicillamine derivative 1c furnished 2c with much better enantioselectivity than that of the cysteine derivative $\mathbf{2 b}$. Interestingly, both the electrochemically obtained product and the chemical product had high enantiomeric excess, $91 \%$ ee and $86 \%$ ee, respectively. It was, therefore deduced that the bulkiness of the ring as well as the $N$-protecting group exclusively favored the formation of one stereoisomer by memory of chirality. The methoxyl group was introduced through retention mechanism and this enantiomeric excess, 91\% ee, represents the highest ever-reported memory of chirality via carbenium ion intermediate. 


\section{REFERENCES AND NOTES}

1. T. Kawabata, K. Yashiro, and K. Fuji, J. Am. Chem. Soc., 1991, 113, 9694; D. Seebach, A. R. Sting, and M. Hoffmann, Angew. Chem. Int. Ed. Engl., 1996, 35, 2708; K. Fuji and T. Kawabata, Chem. Eur. J., 1998, 4, 373; A. G. Griesbeck, W. Kramer, A. Bartoschek, and H. Schmickler, Org. Lett., 2001, 3, 537; T. Kawabata, S. Matsuda, S. Kawakami, D. Monguchi, and K. Moriyama, J. Am. Chem. Soc., 2006, 128, 15394; T. Kawabata, K. Moriyama, S. Kawakami, and K. Tsubaki, J. Am. Chem. Soc., 2008, 130, 4153; M. Branca, S. Pena, R. Guillot, D. Gori, V. Alezra, and C. Kouklovsky, J. Am. Chem. Soc., 2009, 131, 10711.

2. Y. Matsumura, T. Tanaka, G. N. Wanyoike, T. Maki, and O. Onomura, J. Electroanal. Chem., 2001, 507, 71; Y. Matsumura, G. N. Wanyoike, O. Onomura, and T. Maki, Electrochim. Acta, 2003, 48, 2957; G. N. Wanyoike, Y. Matsumura, and O. Onomura, Heterocycles, 2009, 79, 339.

3. G. N. Wanyoike, O. Onomura, T. Maki, and Y. Matsumura, Org. Lett., 2002, 4, 1875.

4. Y. Matsumura, Y. Shirakawa, Y. Satoh, M. Umino, T. Tanaka, T. Maki, and O. Onomura, Org. Lett., 2000, 2, 1689.

5. Typical procedure: A solution of cysteine derivative $1(0.5 \mathrm{mmol})$ and $\mathrm{NaOMe}(5 \mathrm{mmol})$ in methanol $(10 \mathrm{~mL})$ was put into an undivided cell, stirred continuously and cooled to $-30^{\circ} \mathrm{C}$. The cell was then equipped with platinum plate electrodes $(1 \mathrm{~cm} \times 2 \mathrm{~cm})$. Electrolysis of the solution with $2 \mathrm{~F} / \mathrm{mol}$ at a constant current (50 mA) afforded 2 at $2 \mathrm{~F} / \mathrm{mol}$.

6. 4-Methoxy-2,2-dimethyl-3-o-phenylbenzoylthiazolidine (2b): 58\% yield, Colorless oil. HPLC analysis; Daicel chiralcel OD $(0.46 \mathrm{~cm} \phi$ x $50 \mathrm{~cm})$; $n$-hexane:2-propanol=30:1; wavelength, $210 \mathrm{~nm}$; flow rate $0.5 \mathrm{~mL} / \mathrm{min}$; retention time, $30.1 \mathrm{~min}$ (major), $44.9 \mathrm{~min}$ (minor), $85.5 \%$ ee; $[\alpha]_{\mathrm{D}}^{26.7}-67.7$ (c 0.5, $\left.\mathrm{CHCl}_{3}\right) ;{ }^{1} \mathrm{H}-\mathrm{NMR}\left(300 \mathrm{MHz}, \mathrm{CDCl}_{3}\right) \delta$ 7.60-7.40 (m, 9H), 4.65 (d, 1H, J=3.0 Hz), 2.87 (s, 3H), 2.55 (d, 1H, $J=12.4 \mathrm{~Hz}), 2.10(\mathrm{dd}, 1 \mathrm{H}, J=3.60,12.4 \mathrm{~Hz}), 1.97$ (s, 3H), $1.64(\mathrm{~s}, 3 \mathrm{H}) ;{ }^{13} \mathrm{C} \mathrm{NMR}(100 \mathrm{~Hz}$, $\left.\mathrm{CDCl}_{3}\right) \delta 169.41$ (1C), 139.36 (1C), 137.94 (1C), 137.07 (1C), 129.50 (1C), 129.14 (1C), 128.98 (2C), 128.77 (1C), 128.61 (2C), 127.99 (1C), 127.48 (1C) 93.62 (1C), 71.75 (1C), 55.02 (1C), 33.10 (1C), 29.79 (1C), 28.44 (1C); IR (neat) 3050, 2977, 2930, 2828, 1657, 1605, 1580, 1478, 1372, 1182, 1073, 900, 891, 793, 747, $702 \mathrm{~cm}^{1}$. HR-MS [FAB(+)]: m/z calcd for $\mathrm{C}_{19} \mathrm{H}_{22} \mathrm{NO}_{2} \mathrm{~S}[\mathrm{M}+\mathrm{H}]^{+}$ 328.1371, found: 328.1389 .

7. 4-Methoxy-2,2,5,5-tetramethyl-3-o-phenylbenzoylthiazolidine (2c): 54\% yield, HPLC analysis; Daicel Chiralcel OD (0.46 cm $\phi$ x $25 \mathrm{~cm})$; $n$-hexane: 2-propanol=50:1; wavelength, $210 \mathrm{~nm}$; flow rate $0.5 \mathrm{~mL} / \mathrm{min}$; retention time, $14.2 \mathrm{~min}$ (minor), $28.3 \mathrm{~min}$ (major), $91 \%$ ee; $\mathrm{Mp} 66-68^{\circ} \mathrm{C}$ (uncorrected); $[\alpha]^{27.7} 44.6\left(\mathrm{c} 0.5, \mathrm{CHCl}_{3}\right) ;{ }^{1} \mathrm{H}-\mathrm{NMR}\left(300 \mathrm{MHz}, \mathrm{CDCl}_{3}\right) \delta$ 7.70-7.28 (m, 9H), $4.02(\mathrm{~s}, 1 \mathrm{H}), 2.80$ (s, $3 \mathrm{H}), 1.93$ (s, 3H), 1.82 (s, 3H), 1.12 (s, 3H), 0.47 (s, 3H); IR (neat) 3050, 2924, 2853, 1655, 1466, 
1387, 1182, 1223, 1073, 745, $702 \mathrm{~cm}^{-1}$; EA Calcd. For $\mathrm{C}_{21} \mathrm{H}_{24} \mathrm{NO}_{2} \mathrm{~S}$ C, 70.95; H, 7.09; N, 3.94; Found C, 71.01; H, 6.86; N, 3.60.

8. Cross peaks of the NOESY spectrum for 1d were observed between H-4 and 5-methyl, 2a-methyl group, 2a-methyl group and 5-methyl, $2 \boldsymbol{b}$-methyl group and H-5. With this result, the structure of $\mathbf{1 d}$
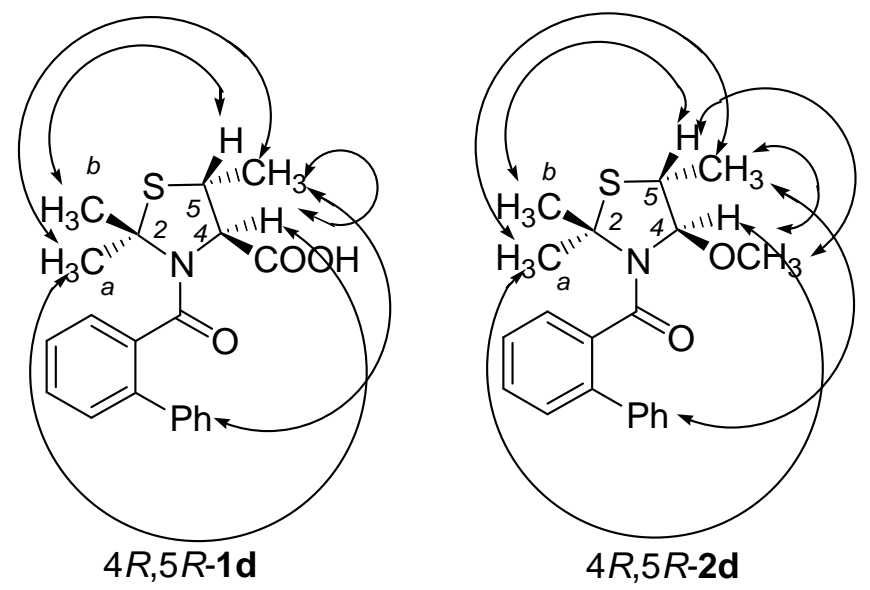

Figure 1. NOESY for $\mathbf{1 d}$ and $\mathbf{2 d}$.

was deduced as shown in Figure 1. Also, NOESY analysis of 2d showed strong NOE between the methoxyl protons and H-5, H-4 and 5-methyl protons. These were the main diagnostic peaks for the assignment of the configuration although other cross peaks were also observed as shown in Figure 1.

9. T. Wakamiya, K. Shimbo, T. Shiba, K. Nakajima, M. Neya, K. Okawa, Bull. Chem. Soc. Jpn, 1982, 55,3878 . 